\title{
Molecular characterization of fluoroquinolone and/or cephalosporin resistance in Shigella sonnei isolates from yaks
}

\author{
Zhen Zhu ${ }^{1,2+}$, Yuxiang Shi ${ }^{2 \dagger}$, Xuzheng Zhou', Bing $\mathrm{Li}^{1}$ and Jiyu Zhang ${ }^{1 *}$ [D
}

\begin{abstract}
Background: Members of the genus Shigella are intestinal pathogens and a major cause of seasonal outbreaks of bacterial diarrhea worldwide. Although humans are the conventional hosts of Shigella species, expansion of the Shigella host range to certain animals was recently reported. To investigate the prevalence of Shigella sonnei (S. sonnei) in yaks and perform molecular characterization, we analyzed 1132 fresh yak diarrheal stool samples and collected a total of 44 S. sonnei isolates.

Results: We performed multilocus sequence typing (MLST) and pulsed-field gel electrophoresis (PFGE) with Xbaldigested DNA to study genetic relatedness among the 44 isolates, which were differentiated into 4 sequence types (STs) and 32 PFGE types (PTs). All isolates harbored virulence genes, and $87.36 \%$ tested positive for invasion plasmid antigen $\mathrm{H}$ (ipah), invasion associated locus (ial) and the Shigella enterotoxin gene sen. According to the results of antimicrobial susceptibility tests, 45.45\% (20/44) were resistant to fluoroquinolones and/or cephalosporin. By sequencing the quinolone resistance determining region (QRDR) genes, we identified double mutations in gyrA (Ser83-Leu and Asp87-Asn) and a single mutation in parC (Ser80-lle). All 12 fluoroquinolone-resistant S. sonnei isolates tested positive for the $a a c\left(6^{\prime}\right)-l b-c r$ gene but negative for qepA. Three isolates harbored qnr genes, including two with qnrS and one with anrB. In addition, three types of $\beta$-lactamase genes, bla $a_{T E M-1}$, bla $a_{O X A-1}$ and bla $a_{C T X-M-14 / 79,}$ were detected in cephalosporin-resistant isolates.
\end{abstract}

Conclusions: The findings of this study have enriched our knowledge of fluoroquinolone- and/or cephalosporinresistant S. sonnei isolates from yaks, which has important public health significance.

Keywords: Shigella sonnei, MLST, PFGE, Virulence gene, Antimicrobial resistance genes

\section{Background}

Bacteria of the genus Shigella are important members of the Enterobacteriaceae family and cause acute diarrhea in humans and animals [1-3]. This pathogen has been historically divided into 4 subgroups based on biochemical properties and group-specific $\mathrm{O}$ antigens in the outer membrane, specifically subgroups A

\footnotetext{
* Correspondence: infzjy@sina.com

${ }^{\dagger}$ Zhen Zhu and Yuxiang Shi contributed equally to this work.

${ }^{1}$ Key Laboratory of New Animal Drug Project of Gansu Province, Key

Laboratory of Veterinary Pharmaceutical Development of the Ministry of

Agriculture, Lanzhou Institute of Husbandry and Pharmaceutical Sciences of

CAAS, Jiangouyan, Qilihe District, Lanzhou 730050, China

Full list of author information is available at the end of the article
}

(S. dysenteriae), B (S. flexneri), C (S. boydii) and D (S. sonnei). All four Shigella species cause shigellosis and are phylogenetically distinct from Escherichia coli $[4,5]$, with S. flexneri and S. sonnei being the most prevalent. Notably, $S$. sonnei has become the dominant subgroup in Asian countries in recent years $[6,7]$.

The specific pathogenicity of a given Shigella isolate is derived from the expression of diverse virulence genes that are associated with colonization, invasion/penetration and toxin-mediated disease [8]. The pathogenicity of these virulence genes is often multifactorial, and they are coordinately regulated [9]. An investigation of the virulence determinant genes in Shigella would help us

(c) The Author(s). 2018 Open Access This article is distributed under the terms of the Creative Commons Attribution 4.0 International License (http://creativecommons.org/licenses/by/4.0/), which permits unrestricted use, distribution, and reproduction in any medium, provided you give appropriate credit to the original author(s) and the source, provide a link to the Creative Commons license, and indicate if changes were made. The Creative Commons Public Domain Dedication waiver (http://creativecommons.org/publicdomain/zero/1.0/) applies to the data made available in this article, unless otherwise stated. 
better understand its pathogenicity. However, knowledge regarding the distribution of these genes in Shigella isolates from animals is limited.

For Shigella infections, prompt therapy with effective antimicrobial agents reduces the duration and severity of illness [10]. However, the progressive increase in resistance to commonly used antimicrobials, especially fluoroquinolones and extended-spectrum cephalosporins, among Shigella spp. poses a major therapeutic challenge to the control of diseases caused by these species $[10,11]$. In addition, the emergence and global dissemination of multi-drug resistant (MDR) pathogens is increasing rapidly due to the unique ability of bacteria to acquire resistance factors (transmissible genes) from the environment or from other bacteria [12].

Foodborne pathogens are usually carried by the host animal and contaminate the food during the slaughtering process [13]. And food is the main route to human infection with Shigella, including antibiotic-resistant strains [14]. Foods implicated in human cases of shigellosis include fresh fruit and vegetables, raw oysters, deli meats, and unpasteurized milk [15]. Multidrug-resistant Shigella has been found in bovine-derived foods such as beef, milk and cheese, which predict potential threats to human [16].

The primary goal of this study was to investigate the incidence of $S$. sonnei in yaks with diarrheal disease in a plateau area. We analyzed the biochemical and serological characteristics, virulence gene profiles, antimicrobial resistance profiles, antimicrobial resistance genes (ARGs) and genotypes and genetic relatedness diversity of $S$. sonnei isolates.

\section{Results}

\section{Identification of S. sonnei isolates}

A total of 44 S. sonnei isolates were collected from 1132 fresh diarrheal stool samples from yaks in three Chinese provinces, Gansu, Qinghai and Tibet, from 2014 to 2016. Among these isolates, 24 (54.55\%) were collected from Gansu, 15 (34.09\%) were collected from Qinghai, and 5 (11.36\%) were collected from Tibet. Based on the results of biochemical characterization assays, we observed that all 44 S. sonnei isolates possessed the typical biochemical features of Shigella species and demonstrated the ability to ferment I-D-galactopyranoside (ONPG), glucose (GLU), mannitol (MAN), melibiose (MEL) and arabinose (ARA). Although both serotypes were isolated in each region, phase I $(33 / 44,75 \%)$ was the predominant serotype, and the detection rate of $S$. sonnei phase I was three times higher than that of phase II (11/44, 25\%).

\section{MLST-based genotype analysis}

MLST was performed to analyze the genotypic diversity of S. sonnei isolates based on 15 housekeeping genes. The 44 isolates were divided into 4 sequence types (STs): ST76, ST116, ST125 and ST155. All four STs were previously reported and belonged to the same clonal complex (CC; CC29). The allele number for each locus and the ST designation are listed in Additional file 1: Table S1 and shared on the EcMLST website. Among these STs, ST116 $(n=27)$ and ST155 $(n=13)$ were the most common, accounting for 90.91\% of all STs. ST116 encompassed 16 phase I and 11 phase II serotype isolates; furthermore, all phase II serotype S. sonnei isolates in the study were ST116. Interestingly, all four STs were detected in Gansu province, while only ST116 was observed in Qinghai and Tibet provinces (Table 1).

\section{PFGE-based genotype analysis}

The genotypes and genetic relatedness diversity of the 44 S. sonnei isolates were assessed by PFGE. At $80 \%$ similarity, $\mathrm{XbaI}$-digested $S$. sonnei DNA generated 32 reproducible unique PFGE banding patterns (PT), yielding three major groups: A $(n=17), \mathrm{B}(n=25)$, and C $(n=2)$ (Fig. 1). Most isolates contained in PT group A were collected from the same geographical region (Gansu province) with the exception of one Tibet isolate (SS036). Group B contained the highest number of isolates, accounting for $56.82 \%$ of total isolates. In addition, almost all Qinghai isolates were clustered in group B2, with the exception of SS017. Interestingly, we also observed that different serotypes affect the PT cluster. In this study, all 17 group A isolates belonged to the phase I serotype, while all of the phase II isolates clustered into group B. The large number of PT types suggested a capricious genotypic and genetic diversity among S. sonnei strains, which adapt to different environments.

Table 1 Statistical analysis of the distribution of 4 MLST types among 44 S. sonnei isolates in different provinces

\begin{tabular}{|c|c|c|c|c|c|c|c|c|}
\hline \multirow{2}{*}{$\begin{array}{l}\text { MLST } \\
\text { types }\end{array}$} & \multicolumn{2}{|l|}{ Total $(n=44)$} & \multicolumn{2}{|l|}{ Gansu $(n=24)$} & \multicolumn{2}{|l|}{ Qinghai $(n=15)$} & \multicolumn{2}{|l|}{ Tibet $(n=5)$} \\
\hline & phase I $(n=33)$ & phase $\|(n=11)$ & phase I $(n=20)$ & phase $\|(n=4)$ & phase I $(n=10)$ & phase $\|(n=5)$ & phase I $(n=3)$ & phase $\|(n=2)$ \\
\hline ST76 & $1(3.03 \%)$ & 0 & $1(5 \%)$ & 0 & 0 & 0 & 0 & 0 \\
\hline ST116 & $16(48.48 \%)$ & 11 (100\%) & $3(15 \%)$ & $4(100 \%)$ & $10(100 \%)$ & $5(100 \%)$ & $3(100 \%)$ & $2(100 \%)$ \\
\hline ST123 & $3(9.09 \%)$ & 0 & $3(15 \%)$ & 0 & 0 & 0 & 0 & 0 \\
\hline ST155 & $13(39.39 \%)$ & 0 & $13(65 \%)$ & 0 & 0 & 0 & 0 & 0 \\
\hline
\end{tabular}




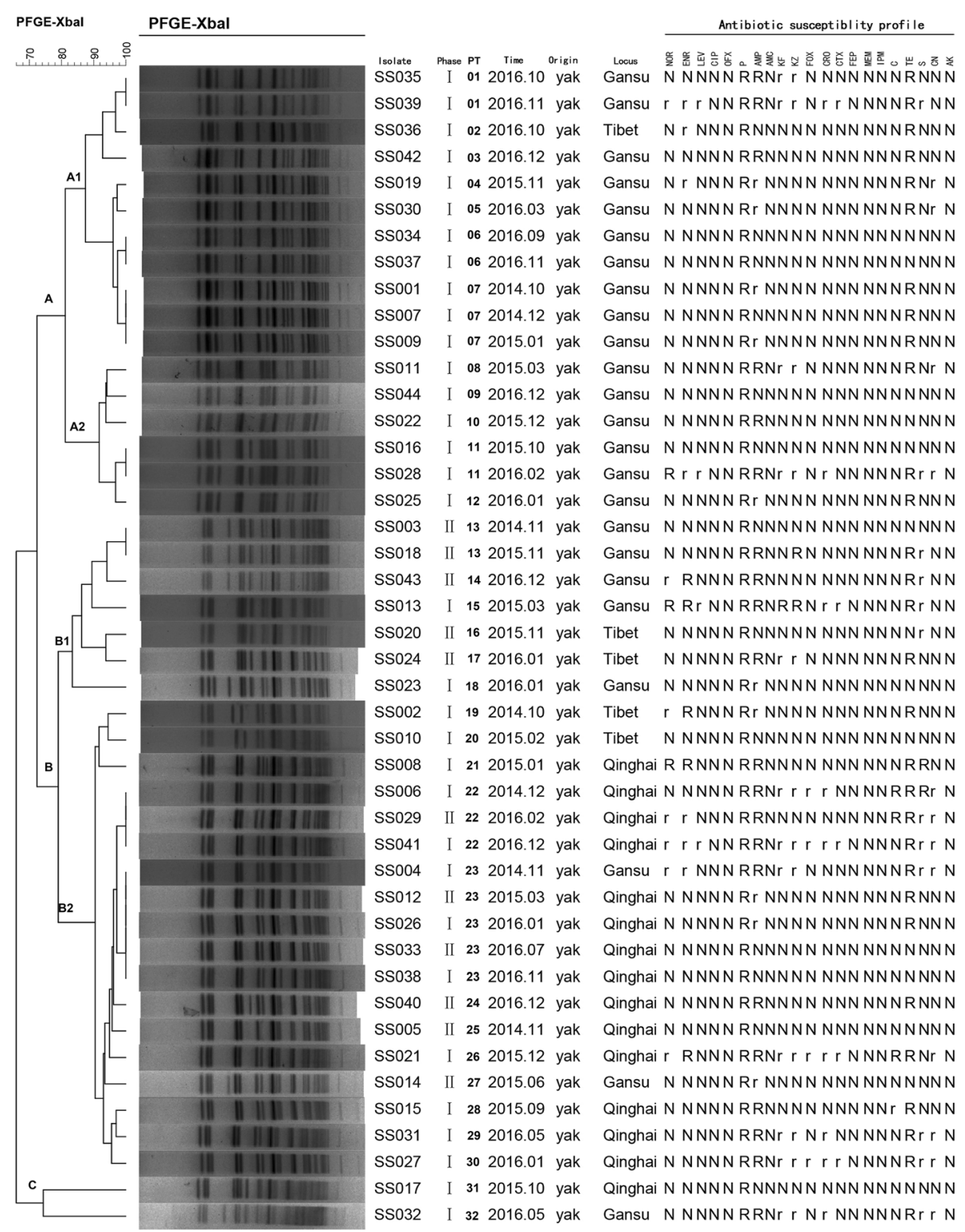

Fig. 1 Dendrogram of 44 Xbal-digested S. sonnei isolates based on the cluster analysis of PFGE patterns. The dendrogram was constructed using the UPGMA clustering method. The corresponding antibiotic resistance profile, PFGE pattern and background information for each strain is listed on the right side of the dendrogram. $\mathrm{R}=$ resistance and no bacteriostatic ring; $r=$ resistance and positive bacteriostatic ring; $N=$ sensitive and intermediary bacteriostatic ring

\section{Virulence genes}

The virulence gene profiles of the isolates are listed in Additional file 2: Table S2. Only 3 virulence genes (ipaH, ial and sen) were observed in this study. Among them, the invasive plasmid gene ipaH was observed in all isolates, followed by ial (38/44, 86.36\%) and sen (37/44, 84.09\%). All isolates tested negative for $\operatorname{set} 1 A$, set $1 B$ and stx.

According to their virulence gene distribution, the 44 S. sonnei isolates formed 3 gene profile patterns (Additional file 3: Table S3). VT3, which was positive for $i p a H$, ial and sen, contained the highest number of isolates $(37,87.36 \%$ ) and was the major VT present in each province. VT2, which was positive for ipaH and ial, was only detected in one Qinghai isolate (SS005). Six isolates (13.64\%), one in Gansu and five in Qinghai, belonged to VT1, which was only positive for ipaH.

\section{Antimicrobial susceptibility profiles}

The antimicrobial resistance profiles of the 44 S. sonnei isolates to 21 antimicrobials are listed in Fig. 1 and Table 2. The antimicrobial susceptibility results showed that all S. sonnei isolates were sensitive to ciprofloxacin, 
Table 2 Statistical analysis of the results of antimicrobial susceptibility testing of 21 antibiotics for 44 S. sonnei isolates

\begin{tabular}{|c|c|c|c|c|c|c|c|}
\hline \multirow[t]{3}{*}{ Antimicrobial } & \multicolumn{7}{|c|}{ Antimicrobial resistance rate $[\mathrm{No} .(\%)]$} \\
\hline & \multirow{2}{*}{$\begin{array}{l}\text { Total } \\
(n=44)\end{array}$} & \multicolumn{2}{|l|}{ Gansu $(n=24)$} & \multicolumn{2}{|l|}{ Qinghai $(n=15)$} & \multicolumn{2}{|l|}{ Tibet $(n=5)$} \\
\hline & & phase I $(n=20)$ & phase II $(n=4)$ & phase I $(n=10)$ & phase $\|(n=5)$ & phase I $(n=3)$ & phase $\|(n=2)$ \\
\hline Norfloxacin & $10(22.73 \%)$ & $4(20 \%)$ & $1(25 \%)$ & $3(30 \%)$ & $1(20 \%)$ & $1(33.33 \%)$ & 0 \\
\hline Enrofloxacin & $12(27.27 \%)$ & $5(25 \%)$ & $1(25 \%)$ & $3(30 \%)$ & $1(20 \%)$ & $2(66.67 \%)$ & 0 \\
\hline Levofloxacin & $4(9.09 \%)$ & $3(15 \%)$ & 0 & $1(10 \%)$ & 0 & 0 & 0 \\
\hline Ciprofloxacin & 0 & 0 & 0 & 0 & 0 & 0 & 0 \\
\hline Ofloxacin & 0 & 0 & 0 & 0 & 0 & 0 & 0 \\
\hline Penicillin G & $44(100 \%)$ & $20(100 \%)$ & $4(100 \%)$ & $10(100 \%)$ & $5(100 \%)$ & $3(100 \%)$ & $2(100 \%)$ \\
\hline Ampicillin & $31(70.45 \%)$ & $15(75 \%)$ & $3(75 \%)$ & $8(80 \%)$ & $3(60 \%)$ & $1(33.33 \%)$ & $1(50 \%)$ \\
\hline Amoxicillin/clavulanic acid & 0 & 0 & 0 & 0 & 0 & 0 & 0 \\
\hline Cephalothin & $13(29.55 \%)$ & $7(35 \%)$ & 0 & $5(50 \%)$ & 0 & 0 & $1(50 \%)$ \\
\hline Cephazolin & $14(31.82 \%)$ & $7(35 \%)$ & $1(25 \%)$ & $5(50 \%)$ & 0 & 0 & $1(50 \%)$ \\
\hline Cefoxitin & $4(9.09 \%)$ & 0 & 0 & $4(40 \%)$ & 0 & 0 & 0 \\
\hline Ceftriaxone & $9(20.45 \%)$ & $4(20 \%)$ & 0 & $5(50 \%)$ & 0 & 0 & 0 \\
\hline Cefotaxime & $5(11.36 \%)$ & $2(10 \%)$ & 0 & $3(30 \%)$ & 0 & 0 & 0 \\
\hline Cefepime & 0 & 0 & 0 & 0 & 0 & 0 & 0 \\
\hline Meropenem & 0 & 0 & 0 & 0 & 0 & 0 & 0 \\
\hline Imipenem & 0 & 0 & 0 & 0 & 0 & 0 & 0 \\
\hline Chloramphenicol & $4(9.09 \%)$ & 0 & 0 & $3(30 \%)$ & $1(20 \%)$ & 0 & 0 \\
\hline Tetracycline & $30(68.18 \%)$ & 14 (70\%) & $2(50 \%)$ & $8(80 \%)$ & $3(60 \%)$ & 2 (66.67\%) & $1(50 \%)$ \\
\hline Streptomycin & $14(31.82 \%)$ & $5(25 \%)$ & $2(50 \%)$ & $5(50 \%)$ & $1(20 \%)$ & 0 & $1(50 \%)$ \\
\hline Gentamicin & $12(27.27 \%)$ & $6(30 \%)$ & 0 & $5(50 \%)$ & $1(20 \%)$ & 0 & 0 \\
\hline Amikacin & 0 & 0 & 0 & 0 & 0 & 0 & 0 \\
\hline
\end{tabular}

ofloxacin, amoxicillin/clavulanic acid, cefepime, meropenem, imipenem, and amikacin but resistant to penicillin $\mathrm{G}$. The resistance rates to other antimicrobials are as follows: ampicillin (31/44, 70.45\%), tetracycline (30/44, 68.18\%), cephazolin $(14 / 44,31.82 \%)$, streptomycin $(14 / 44,31.82 \%)$, cephalothin $(13 / 44,29.55 \%)$, enrofloxacin (12/44, 27.27\%), gentamicin (12/44, 27.27\%), norfloxacin (10/44, 22.73\%), ceftriaxone (9/44, 20.45\%), cefotaxime $(5 / 44,11.36 \%)$, levofloxacin (4/44, 9.09\%), cefoxitin (4/44, 9.09\%), and chloramphenicol (4/44, $9.09 \%$ ). Although the observed resistance to most antimicrobials (with the exception of penicillin G, ampicillin and tetracycline) was less than 50\%, multidrug-resistant (MDR) S. sonnei isolates, which were defined as being resistant to 3 or more antimicrobial agent subclasses, accounted for $43.18 \%$ of isolates (19/44).

Remarkably, the rates of resistance to fluoroquinolones and cephalosporin were $27.275 \%(12 / 44)$ and $31.82 \%$ $(14 / 44)$, respectively, and $13.64 \%(6 / 44)$ of isolates were resistant to both fluoroquinolones and cephalosporin. Moreover, all fluoroquinolone-resistant isolates belonged to the MDR group. Interestingly, the fluoroquinoloneand/or cephalosporin-resistant isolates demonstrated diverse antimicrobial resistance profiles, and no isolates had the same resistance profile (Table 3 and Fig. 1).

\section{Molecular analysis of antimicrobial resistance determinants}

In the present study, all four QRDR genes ( $g y r A, \operatorname{gyr} B$, parC, and parE) were sequenced and compared with reference sequences. According to the results, double mutations in gyrA (Ser83-Leu and Asp87-Asn) and a single mutation in parC (Ser80-Ile) were associated with fluoroquinolone resistance in S. sonnei isolates (Table 3). The encoded Ser83-Leu amino acid substitution in gyr $A$ was observed in every fluoroquinolone-resistant isolate, and $66.67 \%(8 / 12)$ of fluoroquinolone-resistant isolates possessed the Asp87-Asn mutation in gyrA. Only four isolates harbored all three amino acid substitutions. Interestingly, all four of these isolates belonged to the phase I serotype.

In addition to the identification of substitutions in QRDR genes, PMQR genes were amplified and sequenced. According to the results, all fluoroquinolone-resistant isolates harbored the $a a c\left(6^{\prime}\right)-I b-c r$ gene. The qepA gene, which encodes an efflux pump, was not observed in the 
Table 3 Analysis of amino acid types in QRDRs and ARGs in S. sonnei isolates with resistance to fluoroquinolones and/or cephalosporin

\begin{tabular}{|c|c|c|c|c|c|c|c|c|c|}
\hline & \multirow[t]{4}{*}{ Antimicrobial resistance profiles } & \multicolumn{5}{|c|}{ Fluoroquinolone resistance genes } & \multicolumn{3}{|c|}{ Cephalosporin resistance genes } \\
\hline & & \multicolumn{3}{|l|}{ QRDR } & \multicolumn{2}{|l|}{ PMQR genes } & \multirow[t]{3}{*}{ TEM } & \multirow[t]{3}{*}{ OXA } & \multirow[t]{3}{*}{$C T X-M$} \\
\hline & & \multicolumn{2}{|l|}{ gyrA } & \multirow{2}{*}{$\begin{array}{l}\text { parC } \\
80(\mathrm{~S})\end{array}$} & \multirow[t]{2}{*}{$a a c\left(6^{\prime}\right)-1 b-c r$} & \multirow[t]{2}{*}{$q n r$} & & & \\
\hline & & $83(S)$ & $87(\mathrm{D})$ & & & & & & \\
\hline $\begin{array}{l}\text { Strain } \\
\text { name }\end{array}$ & \multirow{2}{*}{$\begin{array}{l}\text { ENR/TE } \\
\text { ENR/AMP/TE/CN }\end{array}$} & L & $\mathrm{D}$ & $\mathrm{S}$ & $a a c\left(6^{\prime}\right)-1 b-c r$ & NA & - & - & - \\
\hline ENR/AMP/TE/CN & & L & $\mathrm{D}$ & $\mathrm{S}$ & $\operatorname{aac}\left(6^{\prime}\right)-1 b-c r$ & NA & - & - & - \\
\hline SS002 & NOR/ENR/AMP/TE & L & $\mathrm{D}$ & $\mathrm{S}$ & $\operatorname{aac}\left(6^{\prime}\right)-1 b-c r$ & NA & - & - & - \\
\hline SS008 & NOR/ENR/AMP/TE/S & L & $\mathrm{N}$ & $S$ & $\operatorname{aac}\left(6^{\prime}\right)-1 b-c r$ & qnrB & - & - & - \\
\hline SSO43 & NOR/ENR/AMP/TE/S & L & $\mathrm{D}$ & I & $\operatorname{aac}\left(6^{\prime}\right)-1 b-c r$ & NA & - & - & - \\
\hline SS029 & NOR/ENR/AMP/C/TE/S/CN & L & N & S & $\operatorname{aac}\left(6^{\prime}\right)-1 b-c r$ & NA & - & - & - \\
\hline SS018 & AMP/KZ/TE/S & - & - & - & - & - & TEM-1 & NA & NA \\
\hline SS024 & $\mathrm{AMP} / \mathrm{KF} / \mathrm{KZ} / \mathrm{TE}$ & - & - & - & - & - & TEM-1 & NA & NA \\
\hline SS035 & $\mathrm{AMP} / \mathrm{KF} / \mathrm{KZ} / \mathrm{TE}$ & - & - & - & - & - & TEM-1 & NA & NA \\
\hline SS011 & AMP/KF/KZ/TE/CN & - & - & - & - & - & TEM-1 & NA & NA \\
\hline SS031 & AMP/KF/KZ/CRO/TE/S/CN & - & - & - & - & - & TEM-1 & $O X A-1$ & NA \\
\hline SS032 & AMP/KF/KZ/CRO/TE/S/CN & - & - & - & - & - & TEM-1 & $O X A-1$ & NA \\
\hline SS006 & AMP/KF/KZ/FOX/CRO/C/TE/S/CN & - & - & - & - & - & TEM-1 & $O X A-1$ & NA \\
\hline SS027 & AMP/KF/KZ/FOX/CRO/CTX/TE/S/CN & - & - & - & - & - & TEM-1 & NA & CTX-M-79 \\
\hline SSO04 & NOR/ENR/AMP/KF/KZ/TE/S/CN & L & $\mathrm{N}$ & $\mathrm{S}$ & $\operatorname{aac}\left(6^{\prime}\right)-1 b-c r$ & NA & TEM-1 & $O X A-1$ & NA \\
\hline SS028 & NOR/ENR/LEV/AMP/KF/KZ/CRO/TE/S/CN & L & $\mathrm{N}$ & । & $\operatorname{aac}\left(6^{\prime}\right)-1 b-c r$ & NA & TEM-1 & $O X A-1$ & NA \\
\hline SS013 & NOR/ENR/LEV/AMP/KF/KZ/CRO/CTX/TE/S & L & N & I & $\operatorname{aac}\left(6^{\prime}\right)-1 b-c r$ & NA & TEM-1 & $O X A-1$ & CTX-M-14 \\
\hline SS039 & NOR/ENR/LEV/AMP/KF/KZ/CRO/CTX/TE/S & L & $\mathrm{N}$ & । & $\operatorname{aac}\left(6^{\prime}\right)-1 b-c r$ & NA & TEM-1 & $O X A-1$ & CTX-M-14 \\
\hline SS021 & NOR/ENR/AMP/KF/KZ/FOX/CRO/CTX/C/TE/CN & L & N & $\mathrm{S}$ & $\operatorname{aac}\left(6^{\prime}\right)-1 b-c r$ & anrs & TEM-1 & $O X A-1$ & CTX-M-14 \\
\hline SS041 & NOR/ENR/LEV/AMP/KF/KZ/FOX/CRO/CTX/TE/S/CN & L & $\mathrm{N}$ & । & $\operatorname{aac}\left(6^{\prime}\right)-1 b-c r$ & qnrs & TEM-1 & $O X A-1$ & CTX-M-14 \\
\hline
\end{tabular}

S Ser, L Leu, D Asp, N Asn, I lle, NA not available; "-": not detected

studied isolates. Only three Qinghai isolates tested positive for the $q n r$ gene, with two having qnrS and one having qnrB (Table 3).

For the 14 cephalosporin-resistant isolates, only three $\beta$-lactamase gene types $\left(b l a_{T E M}, b l a_{O X A}\right.$ and $\left.b l a_{C T X-M}\right)$ were observed. All isolates tested positive for the $b l a_{T E M}$ gene and showed $100 \%$ identity with the $b l a_{T E M-1}$ subtype. And all the third-cephalosporin resistant isolates were positive for $b l a_{O X A}\left(b l a_{O X A-1}\right)$, except SS027. Five out of the fourteen cephalosporin-resistant isolates tested positive for $b l a_{C T X-M}, 4$ of which had the $b l a_{C T X-M-14}$ gene, and 1 had the $b l a_{C T X-M-79}$ gene.

\section{Discussion}

Bacillary dysentery caused by Shigella is endemic throughout the world. Humans are the natural hosts of Shigella, although reports of Shigella infections in animals (fish, calves, piglets, and chickens) have emerged $[2,17-19]$. We previously confirmed the existence of diverse $S$. sonnei isolates in yak in local epidemiological studies. The rate of $S$. sonnei isolation from the diarrhea of yaks was $3.89 \%(44 / 1132)$, and the predominant serotype was phase I, which was isolated three times more frequently than phase II. In addition, 54 S. flexneri isolates with diverse serotypes were reported in our previous study [19].

MLST and PFGE have shown comparable discrimination in terms of their ability to subtype $S$. sonnei. In this study, 44 S. sonnei isolates from yaks were grouped into 4 STs based on 15 housekeeping genes. Comparison of these genes with the standard gene types on the EcMLST website revealed that the different STs of these isolates were primarily attributable to three genes, $\operatorname{asp} C$, $m u t S$, and ropS. In addition, all isolates belonged to the same clonal complex, suggesting a relatively close genetic relationship among them. In our study, the majority of isolates $(n=27$ and $n=13)$ belonged to ST116 and ST155, respectively. However, ST76, ST116, and ST114 were previously reported in human isolates [20, 21]. PFGE is a broadly applicable typing method that has high resolution for the molecular characterization of several enteric bacteria, including Shigella [20]. Based on our PFGE analysis, the $S$. sonnei isolates in the present study were heterogeneous and distributed into 32 PTs. 
The clustering of these diverse PTs allows us to learn more about the epidemiological characteristics of S. son$n e i$ in specific geographical regions. PFGE appeared to have a higher discriminatory power for genotypes and genetic relatedness diversity analysis than MLST.

Virulence genes are responsible for the invasion of virulent Shigella strains into intestinal epithelial cells, resulting in dysentery in hosts [22]. ipaH, which is typically used as a marker of Shigella, was harbored by all isolates. Additionally, in this study, most isolates simultaneously harbored the $i a l$ and sen genes. The diversity of the observed virulence genes suggested the isolates were pathogenic. Moreover, virulence genes were frequently located in megaplasmids, which allow Shigella to acquire and disseminate bacterial invasion genes through mobile genetic elements [23].

Recently, antimicrobial-resistant and MDR S. sonnei isolates have been widely isolated [20, 23]. In this study, we isolated MDR S. sonnei isolates from yaks. More than half of the isolates were resistant to conventional and commonly used antimicrobials: penicillin G (100\%), ampicillin (70.45\%), and tetracycline (68.18\%). Fortunately, for most antimicrobials, the rates and levels of resistance of Shigella isolates from yaks were less than those from isolates from livestock [24]. Notably, although only low rates of resistance and MIC values to fluoroquinolones and/or cephalosporin were observed, some $S$. sonnei had acquired the ability to survive the selective pressures of these antimicrobials, which will limit the control and treatment of shigellosis.

Fluoroquinolone resistance is primarily mediated by the accumulation of sequential mutations in four QRDR genes: gyrA and gyrB, which encode DNA gyrase, and parC and parE, which encode and topoisomerase IV [25]. The primary mutations are located in $g y r A$ and parC. According to a previous study, the major mutations in gyr $A$ codons 81 (Gly $\rightarrow \mathrm{Ser}$ ), 83 (Ser $\rightarrow$ Leu), 87 $(\mathrm{Asp} \rightarrow \mathrm{Asn} / \mathrm{Gly} / \mathrm{Tyr}$ ), and 211 (His $\rightarrow \mathrm{Tyr})$ and $\operatorname{parC}$ codons 80 (Ser $\rightarrow$ Ile), 83 (Ser $\rightarrow$ Leu), and 129 (Ser $\rightarrow$ Pro) are associated with quinolone and/or fluoroquinolone resistance in Shigella [11, 24, 26, 27]. Furthermore, the continuous accumulation of mutations at multiple positions and different mutations at the same position may lead to diverse levels of resistance [23]. In this study, we identified QRDR mutations in all fluoroquinolone-resistant S. sonnei, observing only a few classic amino acid substitutions in $\operatorname{gyr} A$ and parC.

The PMQR determinants are typically located on mobile or transposable genetic elements, which may facilitate dissemination among Shigella species and other members of the Enterobacteriaceae family [28, 29]. Recently, the diversity of PMQR determinants has emerged as an important issue worldwide [27]. Among the PMQR genes, $a a c\left(6^{\prime}\right)-I b-c r$, which encodes aminoglycoside acetyl transferase and is responsible for reduced fluoroquinolone activity, was the most prevalent in our study. The qnr-encoded family of proteins protects DNA gyrase from quinolones and confers low-level resistance [30]. QnrS were majority prevalence in Shigella (S.sonnei and S.flexneri) in China, while $q n r B$ previously in India $[23,26]$. In addition, the plasmid-mediated efflux pump-encoding gene qep $A$ was detected at lower frequencies [27]. The presence of $\mathrm{PMQR}$ genes may help microorganisms develop resistance by conferring mutations and facilitating the selection of higher-level quinolone resistance [31].

ESBLs continue to be the major defense mechanism against cephalosporins among Gram-negative bacteria [32]. Since first being identified in the 1980s, different types of ESBLs belonging to the TEM, OXA, SHV and CTX-M families have been widely reported in Enterobacteriaceae, including Shigella species [33, 34]. The global spread of ESBL-producing Shigella is difficult to control and eradicate because these bacteria reside in the intestines of humans and animals and harbor epidemic resistance plasmids. Therefore, the prevalence of ESBL-producing $S$ sonnei in yaks represents a substantial threat.

\section{Conclusion}

Antimicrobial-resistant Shigella remains a serious threat to humans and animals; however, knowledge of the molecular epidemiology of this pathogen in yaks is limited. Shigella species typically harbor various plasmids that are associated with invasion into host intestinal epithelial cells and antimicrobial resistance and may be transferred between different bacteria. In the present study the $S$. sonnei strains isolated from yaks that tested positive for diverse virulence genes and ARGs represent a potential threat to hosts, including humans. Therefore, continuous and extensive surveillance will be necessary to control and reduce the threat of foodborne pathogens, such as Shigella, Salmonella and E. coli.

\section{Methods}

\section{Bacterial isolates and serological confirmation}

A total of 44 S. sonnei isolates were obtained from yaks with diarrhea from October 2014 to December 2016. All yaks have hardly been exposed to any antibiotic except for a few of penicillin to against the disease. All isolates were collected directly from fresh stool samples, plated on Salmonella-Shigella (SS) selective agar and confirmed on MacConkey (MAC) agar at $37{ }^{\circ} \mathrm{C}$ for 18 to $24 \mathrm{~h}$. Colorless, semitransparent, smooth, and moist circular plaques were considered presumptive Shigella isolates and were selected for further confirmation [34]. The presumptive positive Shigella isolates were identified using API 20 E kits (bioMerieux, Marcy-l'Etoile, France), and serotypes were tested with a commercially available kit 
(Denka Seiken; Tokyo, Japan) according to the manufacturer's recommendations.

\section{Multilocus sequence typing (MLST)}

MLST was performed for each isolate according to the protocols described on the EcMLST website (http://www.shigatox.net/ecmlst). The following PCR amplification conditions were used for 15 housekeeping genes: $94{ }^{\circ} \mathrm{C}$ for $5 \mathrm{~min}$, followed by 30 cycles of $94{ }^{\circ} \mathrm{C}$ for $30 \mathrm{~s}, 55{ }^{\circ} \mathrm{C}$ for $30 \mathrm{~s}$, and $72{ }^{\circ} \mathrm{C}$ for $1 \mathrm{~min}$, with incubation for $10 \mathrm{~min}$ at $72{ }^{\circ} \mathrm{C}$ with ExTaq DNA polymerase (Takara; Dalian, China). The PCR products were sequenced bi-directionally, and sequences of the 15 housekeeping genes were edited using SeqMan 7.0. Finally, the sequences were uploaded to the EcMLST website for comparison, which allowed us to determine the gene and ST type [35].

\section{Pulsed-field gel electrophoresis (PFGE)}

All $S$. sonnei isolates were analyzed for genetic relatedness by PFGE after digestion with the restriction enzyme $X b a \mathrm{I}$ (TaKaRa; Japan) according to the recommendations of a previous study [36]. Salmonella enterica serotype Braenderup strain H9812 was used as a molecular size maker. Electrophoresis was performed with a Bio-Rad CHEF Mapper XA system (Bio-Rad; USA) in a $1 \%$ SeaKem Gold agarose gel (Lonza; USA) in 0.5X TBE buffer with a size range of 30-700 kb. The PFGE run conditions were $6 \mathrm{~V} / \mathrm{cm}$ with a switch from 2.16 to $54.17 \mathrm{~s}$ for $21 \mathrm{~h}$ at $14{ }^{\circ} \mathrm{C}$.

After gel electrophoresis, gels were stained with ethidium bromide, rinsed, and photographed with a Universal Hood II (Bio-Rad; USA). The PFGE patterns were analyzed with BioNumerics using the Dice similarity coefficient, unweighted pair-group method with arithmetic mean (UPGMA) and 1.0\% tolerance.

\section{Detection of virulence genes by PCR}

All $S$. sonnei isolates were examined for the presence of six virulence genes, invasion plasmid antigen $\mathrm{H}(i p a H)$, invasion associated locus (ial), Shiga toxin gene (stx), and Shigella enterotoxin genes (set $1 A$, set $1 B$, and sen), by PCR according to published procedures [23, 37]. The primers for these virulence genes are listed in Additional file 4: Table S4. Amplification products were separated by $1 \%$ agarose gel electrophoresis and stained with ethidium bromide.

\section{Antimicrobial susceptibility}

Antimicrobial susceptibility testing was performed by the Kirby-Bauer disc diffusion method on Muller-Hinton agar (MHA) plates following the guidelines of the Clinical and Laboratory Standards Institute (CLSI) using commercially available antimicrobial discs (Oxoid, UK). Twenty-one antimicrobial discs were used in this study: norfloxacin (NOR, $10 \mu \mathrm{g}$ ), enrofloxacin (ENR, $5 \mu \mathrm{g}$ ), levofloxacin (LEV, $5 \mu \mathrm{g}$ ), ciprofloxacin (CIP, $5 \mu \mathrm{g}$ ), ofloxacin (OFX, $5 \mu \mathrm{g})$, penicillin G (P, $10 \mu \mathrm{g})$, ampicillin (AMP, $10 \mu \mathrm{g}$ ), amoxicillin/clavulanic acid (AMC, $30 \mu \mathrm{g}$ ), cephalothin (KF, $30 \mu \mathrm{g}$ ), cephazolin (KZ, $30 \mu \mathrm{g}$ ), cefoxitin (FOX, $30 \mu \mathrm{g})$, ceftriaxone (CRO, $30 \mu \mathrm{g})$, cefotaxime (CTX, $30 \mu \mathrm{g})$, cefepime (FEP, $30 \mu \mathrm{g})$, imipenem (IPM, $10 \mu \mathrm{g}$ ), meropenem (MEM, $10 \mu \mathrm{g}$ ), chloramphenicol $(\mathrm{C}, 30 \mu \mathrm{g})$, tetracycline ( $\mathrm{TE}, 30 \mu \mathrm{g})$, streptomycin $(\mathrm{S}, 10 \mu \mathrm{g})$, gentamicin $(\mathrm{CN}, 10 \mu \mathrm{g})$, and amikacin (AK, $30 \mu \mathrm{g})$. E. coli ATCC 25922 was used as a control strain. The standard of antibiotic susceptibility for CLSI were list in Additional file 5: Table S5.

Detection of $\beta$-lactamase and quinolone resistance genes Cephalosporin- and/or fluoroquinolone-resistant S. sonnei isolates were assayed by PCR using 24 primer panels to determine the underlying mechanism conferring resistance (Additional file 6: Table S6). Specifically, 6 plasmid-mediated quinolone resistance (PMQRs) determinant genes ( $q n r A$, $q n r B, q n r D, q n r S$, qepA and $\left.a a c\left(6^{\prime}\right)-I b-c r\right)$ and 4 quinolone resistance determining region (QRDR) genes ( $g y r A$, gyrB, parC and parE) were amplified to clarify the underlying mechanism conferring resistance to quinolones [38-40]. Extended-spectrum $\beta$-lactamase (ESBL) genes $\left(b l a_{C T X-M}, b l a_{S H V}, b l a_{T E M}\right.$, and $\left.b l a_{O X A}\right)$ were detected in cephalosporin-resistant isolates [39, 41, 42].

\section{Additional files}

Additional file 1: Table S1. MLST allelic profiles and ST designations of 44 S. sonnei isolates from this study. (DOCX $45 \mathrm{~kb}$ )

Additional file 2: Table S2. Statistical analysis of the presence of virulence genes in each S. sonnei isolate. (DOCX $39 \mathrm{~kb}$ )

Additional file 3: Table S3. Statistical analysis of the occurrence of each virulence gene profile in different provinces. (DOCX $36 \mathrm{~kb}$ )

Additional file 4: Table S4. Primers used to detect virulence genes. (DOCX $39 \mathrm{~kb}$ )

Additional file 5: Table S5. The standard of antibiotic susceptibility for K-B disc-diffusion method. (DOCX $59 \mathrm{~kb}$ )

Additional file 6: Table S6. Primers used to detect antibiotic resistance determinant genes. (DOCX $81 \mathrm{~kb}$ )

\section{Abbreviations}

ESBL: Extended-spectrum $\beta$-lactamase; MLST: Multilocus sequence typing; PFGE: Pulsed-field gel electrophoresis; PMQRs: Plasmid-mediated quinolone resistance; QRDR: Quinolone resistance determining region; VT: Virulence gene profile types

\section{Acknowledgments}

The authors warmly thank to all veterinarians and personnel of the farms that provided the samples for this study.

\section{Funding}

This work was financed by grants from the National Natural Science Foundation of China (31272603, 31101836). 


\section{Availability of data and materials}

All data generated or analysed during this study are included in this published article [and its Additional files]. If the reader requires further information to help interpret the results, please contact the corresponding author.

\section{Authors' contributions}

$\mathrm{ZZ}$ and YXS contributed equally to first author in this work. ZZ conceived, designed, performed the experiments and drafted the manuscript the study. YXS collected the samples from Qinghai, performed PFGE and MLST work. XZZ collected the samples from Gansu and isolated Shigella sonneri. BL participated in PCR and sequencing experiments. JYZ designed the study, helped with and supervised the execution of laboratory work, as well as the statistical interpretation of the data and reviewed the final paper. All authors read and approved the final manuscript.

\section{Ethics approval}

This study has gained ethical approval for this study. Our study was conducted according to the Ethics Committee of Animal Experiments at the Institute of Husbandry and Pharmaceutical Sciences of CAAS in Lanzhou, China. And we gained consent from the owners of the animals for them to be used in the study.

\section{Competing interests}

The authors declare that they have no competing interests.

\section{Publisher's Note}

Springer Nature remains neutral with regard to jurisdictional claims in published maps and institutional affiliations.

\begin{abstract}
Author details
${ }^{1}$ Key Laboratory of New Animal Drug Project of Gansu Province, Key Laboratory of Veterinary Pharmaceutical Development of the Ministry of Agriculture, Lanzhou Institute of Husbandry and Pharmaceutical Sciences of CAAS, Jiangouyan, Qilihe District, Lanzhou 730050, China. ${ }^{2}$ College of Life Science and Food Engineering, Hebei University of Engineering, Hanshan District, Handan 056038, China.
\end{abstract}

\section{Received: 9 February 2018 Accepted: 22 May 2018}

Published online: 07 June 2018

\section{References}

1. Stirling J, Griffith M, Blair I, Cormican M, Dooley JS, Goldsmith CE, Glover SG, Loughrey A, Lowery CJ, Matsuda M, McClurg R, McCorry K, McDowell D, McMahon A, Cherie Millar B, Nagano Y, Rao JR, Rooney PJ, Smyth M, Snelling WJ, XU J, Moore JE. Prevalence of gastrointestinal bacterial pathogens in a population of zoo animals. Zoonoses Public Health. 2008; 55(3):166-72.

2. Shi R, Yang X, Chen L, Chang HT, Liu HY, Zhao J, Wang XW, Wang CQ. Pathogenicity of Shigella in chickens. PLoS One. 2014;9(6):e100264.

3. Parajuli P, Adamski M, Verma NK. Bacteriophages are the major drivers of Shigella flexneri serotype 1c genome plasticity: a complete genome analysis. BMC Genomics. 2017;18(1):722.

4. Pupo GM, Lan R, Reeves PR. Multiple independent origins of Shigella clones of Escherichia coli and convergent evolution of many of their characteristics. Proc Natl Acad Sci U S. 2000;7(19):10567-72.

5. Xia S, Xu B, Huang L, Zhao JY, Ran L, Zhang J, Chen H, Pulsrikarn C, Pornruangwong S, Aarestrup FM, Hendriksen RS. Prevalence and characterization of human Shigella infections in Henan Province, China, in 2006. J Clin Microbiol. 2011;49(1):232-42.

6. Bangtrakulnonth A, Vieira AR, Lo Fo Wong DM, Pornreongwong S, Pulsrikarn C, Sawanpanyalert $P$, Hendriksen RS, Aarestrup FM. Shigella from humans in Thailand during 1993 to 2006: spatial-time trends in species and serotype distribution. Foodborne Pathog Dis. 2008;5(6):773-84

7. Qu F, Bao C, Chen S, Cui E, Guo T, Wang H, Zhang J, Wang H, Tang YW, Mao Y. Genotypes and antimicrobial profiles of Shigella sonnei isolates from diarrheal patients circulating in Beijing between 2002 and 2007. Diagn Microbiol Infect Dis. 2012;74(2):166-70.

8. Zhang CL, Liu QZ, Wang J, Chu X, Shen LM, Guo YY. Epidemic and virulence characteristic of Shigella spp. with extended-spectrum cephalosporin resistance in Xiaoshan District, Hangzhou, China. BMC Infect Dis. 2014;14:260.
9. Qu M, Zhang X, Liu G, Huang Y, Jia L, Liang W, Li X, Wu X, Li J, Yan H, Kan $B$, Wang Q. An eight-year study of Shigella species in Beijing, China: serodiversity, virulence genes, and antimicrobial resistance. J Infect Dev Ctries. 2014;8(7):904-8.

10. Azmi IJ, Khajanchi BK, Akter F, Hasan TN, Shahnaij M, Akter M, Banik A, Sultana $\mathrm{H}$, Hossain MA, Ahmed MK, Faruque SM, Talukder KA. Fluoroquinolone resistance mechanisms of Shigella flexneri isolated in Bangladesh. PLoS One. 2014;9(7):e102533.

11. Sabra AH, Araj GF, Kattar MM, Abi-Rached RY, Khairallah MT, Klena JD, Matar GM. Molecular characterization of ESBL-producing Shigella sonnei isolates from patients with bacilliary dysentery in Lebanon. J Infect Dev Ctries. 2009; 3(4):300-5.

12. Ud-Din Al, Wahid SU, Latif HA, Shahnaij M, Akter M, Azmi IJ, Hasan TN, Ahmed D, Hossain MA, Faruque AS, Faruque SM, Talukder KA. Changing trends in the prevalence of Shigella species: emergence of multi-drug resistant Shigella sonnei biotype $\mathrm{g}$ in Bangladesh. PLoS One. 2013;8(12):e82601.

13. Schlundt J. Emerging food-borne pathogens. Biomed Environ Sci. 2001; 14(1-2):44-52.

14. Newell DG, Koopmans M, Verhoef L, Duizer E, Aidara-Kane A, Sprong H, Opsteegh M, Langelaar M, Threfall J, Scheutz F, van der Giessen J, Kruse H. Food-borne diseases - the challenges of 20 years ago still persist while new ones continue to emerge. Int J Food Microbiol. 2010;139(Suppl 1):S3-15.

15. EFSA (European Food Safety Authority). Scientific opinion of the panel on biological hazards on a request from the European food safety authority on foodborne antimicrobial resistance as a biological hazard. EFSA J. 2008;765:1-87.

16. Ahmed AM, Shimamoto T. Molecular characterization of multidrug-resistant Shigella spp. of food origin. Int J Food Microbiol. 2015;194:78-82.

17. Onyango DM, Wandili S, Kakai R, Waindi EN. Isolation of Salmonella and Shigella from fish harvested from the Winam gulf of Lake Victoria. Kenya J Infect Dev Ctries. 2009;3(2):99-104.

18. Priamukhina NS, Kilesso VA, Tikhomirov ED. Animal carriers of Shigella and their possible epidemiological importance. Zh Mikrobiol Epidemiol Immunobiol. 1984;11:20-4.

19. Maurelli AT, Routh PR, Dillman RC, Ficken MD, Weinstock DM, Almond GW, Orndorff PE. Shigella infection as observed in the experimentally inoculated domestic pig, Sus scrofa domestica. Microb Pathog. 1998;25(4):189-96.

20. Li S, Wang J, Wei X, Liu Y, You L, Luo X, Tang G, Sun Q, Ye C, Xu J, Wang D. Molecular characterization of Shigella sonnei: an increasingly prevalent etiologic agent of shigellosis in Guizhou Province, Southwest of China. PLoS One. 2016;11(5):e0156020.

21. Cheng $T$, Shi X, Yong W, Wang J, Xie G, Ding J. Molecular typing of Shigella sonnei isolates circulating in Nanjing, China, 2007-2011. J Infect Dev Ctries. 2014:8(12):1525-32

22. Ashida H, Ogawa M, Mimuro H, Kobayashi T, Sanada T, Sasakawa C. Shigella are versatile mucosal pathogens that circumvent the host innate immune system. Curr Opin Immunol. 2011;23(4):448-55.

23. Das A, Natarajan M, Mandal J. The emergence of quinolone resistant Shigella sonnei, Pondicherry, India. PLoS One. 2016;11(8):e0160290

24. Zhu Z, Cao M, Zhou X, Li B, Zhang J. Epidemic characterization and molecular genotyping of Shigella flexneri isolated from calves with diarrhea in Northwest China. Antimicrob Resist Infect Control. 2017:6:92.

25. Taneja N, Kumar A, Appannanavar S, Verma G, Sharma M. Plasmid-mediated quinolone resistance in Shigella isolates over a decade in India. J Glob Antimicrob Resist. 2014;2(1):59-60.

26. Cui X, Wang J, Yang C, Liang B, Ma Q, Yi S, Li H, Liu H, Li P, Wu Z, Xie J, Jia L, Hao R, Wang L, Hua Y, Qiu S, Song H. Prevalence and antimicrobial resistance of Shigella flexneri serotype 2 variant in China. Front Microbiol. 2015;6:435.

27. Gu B, Qin TT, Fan WT, Bi RR, Chen Y, Li Y, Ma P. Novel mutations in gyrA and $\operatorname{parC}$ among Shigella sonnei strains from Jiangsu Province of China, 2002-2011. Int J Infect Dis. 2017:59:44-9.

28. Folster JP, Pecic G, Bowen A, Rickert R, Carattoli A, Whichard JM. Decreased susceptibility to ciprofloxacin among Shigella isolates in the United States, 2006 to 2009. Antimicrob Agents Chemother. 2011;55(4):1758-60.

29. Rodríguez-Martínez JM, Machuca J, Cano ME, Calvo J, Martínez-Martínez L, Pascual A. Plasmid-mediated quinolone resistance: two decades on. Drug Resist Updat. 2016;29:13-29.

30. Jacoby GA, Gacharna N, Black TA, Miller GH, Hooper DC. Temporal appearance of plasmid-mediated quinolone resistance genes. Antimicrob Agents Chemother. 2009;53(4):1665-6.

31. Yang H, Duan G, Zhu J, Zhang W, Xi Y, Fan Q. Prevalence and characterisation of plasmid-mediated quinolone resistance and mutations in the gyrase and 
topoisomerase IV genes among Shigella isolates from Henan, China, between 2001 and 2008. Int J Antimicrob Agents. 2013;42(2):173-7.

32. Li J, Li B, Ni Y, Sun J. Molecular characterization of the extended-spectrum beta-lactamase (ESBL)-producing Shigella spp. in Shanghai. Eur J Clin Microbiol Infect Dis. 2015;34(3):447-51.

33. Robin F, Beyrouthy R, Bonacorsi S, Aissa N, Bret L, Brieu N, Cattoir V, Chapuis A, Chardon H, Degand N, Doucet-Populaire F, Dubois V, Fortineau N, Grillon A, Lanotte P, Leyssene D, Patry I, Podglajen I, Recule C, Ros A, ColombCotinat M, Ponties V, Ploy MC, Bonnet R. Inventory of Extended-Spectrum- $\beta$ Lactamase-Producing Enterobacteriaceae in France as assessed by a multicenter study. Antimicrob Agents Chemother. 2017;61(3):e01911-16.

34. Tajbakhsh M, García Migura L, Rahbar M, Svendsen CA, Mohammadzadeh M, Zali MR, Aarestrup FM, Hendriksen RS. Antimicrobial-resistant Shigella infections from Iran: an overlooked problem? J Antimicrob Chemother. 2012:67(5):1128-33.

35. Yang C, Li P, Zhang X, Ma Q, Cui X, Li H, Liu H, Wang J, Xie J, Wu F, Sheng C, Du X, Qi L, Su W, Jia L, Xu X, Zhao J, Xia S, Zhou N, Ma H, Qiu S, Song H. Molecular characterization and analysis of high-level multidrug-resistance of Shigella flexneri serotype 4s strains from China. Sci Rep. 2016;6:29124.

36. Qu F, Cui E, Guo T, Li H, Chen S, Liu L, Han W, Bao C, Mao Y, Tang YW. Nasal colonization of and clonal transmission of methicillin-susceptible Staphylococcus aureus among Chinese military volunteers. J Clin Microbiol. 2010;48(1):64-9.

37. Talukder KA, Mondol AS, Islam MA, Islam Z, Dutta DK, Khajanchi BK, Azmi IJ, Hossain MA, Rahman M, Cheasty T, Cravioto A, Nair GB, Sack DA. A novel serovar of Shigella dysenteriae from patients with diarrhoea in Bangladesh. J Med Microbiol. 2007;56(Pt 5):654-8.

38. Hu LF, Li JB, Ye Y, Li X. Mutations in the GyrA subunit of DNA gyrase and the ParC subunit of topoisomerase IV in clinical strains of fluoroquinoloneresistant Shigella in Anhui. China J Microbiol. 2007;45(2):168-70.

39. Tariq A, Haque A, Ali A, Bashir S, Habeeb MA, Salman M, Sarwar Y. Molecular profiling of antimicrobial resistance and integron association of multidrugresistant clinical isolates of Shigella species from Faisalabad, Pakistan. Can 」 Microbiol. 2012;58(9):1047-54.

40. Colobatiu L, Tabaran A, Flonta M, Oniga O, Mirel S, Mihaiu M. First description of plasmid-mediated quinolone resistance determinants and $\beta$-lactamase encoding genes in non-typhoidal Salmonella isolated from humans, one companion animal and food in Romania. Gut Pathog. 2015;7:16.

41. Zong Z, Partridge SR, Thomas L, Iredell JR. Dominance of blaCTX-M within an Australian extended-spectrum beta-lactamase gene pool. Antimicrob Agents Chemother. 2008;52(11):4198-202.

42. Liu J, Zeng T, Su G, Lin LY, Zhao Y, Yang WQ, Xie WX, Zhao ZG, Li GM. The dissemination mode of drug-resistant genes in Enterobacter cloacae. Indian J Med Microbiol. 2015:33(Suppl):87-92.

\section{Ready to submit your research? Choose BMC and benefit from:}

- fast, convenient online submission

- thorough peer review by experienced researchers in your field

- rapid publication on acceptance

- support for research data, including large and complex data types

- gold Open Access which fosters wider collaboration and increased citations - maximum visibility for your research: over $100 \mathrm{M}$ website views per year

At BMC, research is always in progress.

Learn more biomedcentral.com/submissions 